\title{
Modulation of small leucine-rich proteoglycans (SLRPs) expression in the mouse uterus by estradiol and progesterone
}

\author{
Renato M Salgado, Rodolfo R Favaro, Telma MT Zorn ${ }^{*}$
}

\begin{abstract}
Background: We have previously demonstrated that four members of the family of small leucine-richproteoglycans (SLRPS) of the extracellular matrix (ECM), named decorin, biglycan, lumican and fibromodulin, are deeply remodeled in mouse uterine tissues along the estrous cycle and early pregnancy. It is known that the combined action of estrogen (E2) and progesterone (P4) orchestrates the estrous cycle and prepares the endometrium for pregnancy, modulating synthesis, deposition and degradation of various molecules. Indeed, we showed that versican, another proteoglycan of the ECM, is under hormonal control in the uterine tissues.

Methods: E2 and/or medroxiprogesterone acetate (MPA) were used to demonstrate, by real time PCR and immunoperoxidase staining, respectively, their effects on mRNA expression and protein deposition of these SLRPs, in the uterine tissues.

Results: Decorin and lumican were constitutively expressed and deposited in the ECM in the absence of the ovarian hormones, whereas deposition of biglycan and fibromodulin were abolished from the uterine ECM in the non-treated group. Interestingly, ovariectomy promoted an increase in decorin, lumican and fibromodulin mRNA levels, while biglycan mRNA conspicuously decreased. Hormone replacement with E2 and/or MPA differentially modulates their expression and deposition.

Conclusions: The patterns of expression of these SLRPs in the uterine tissues were found to be hormonedependent and uterine compartment-related. These results reinforce the existence of subpopulations of endometrial fibroblasts, localized into distinct functional uterine compartments, resembling the organization into basal and functional layers of the human endometrium.
\end{abstract}

\section{Background}

The reproductive cycle of human and rodents is characterized by recurring morphophysiological changes in the reproductive organs. The combined action of estrogen (E2) and progesterone (P4) orchestrates the cycle and prepares the endometrium for pregnancy. In the mouse, the cycle is known as estrous cycle and is divided into four different phases, denominated proestrus, estrus, metaestrus and diestrus, each one presenting distinct morphological and molecular features [1].

E2 produced during estrus stimulates epithelial cell proliferation and synthesis of progesterone receptors (PR). On

\footnotetext{
* Correspondence: temtzorn@usp.br

Laboratory of Reproductive and Extracellular Matrix Biology, Department of Cell and Developmental Biology, Institute of Biomedical Sciences, University of São Paulo, São Paulo, Brazil
}

(C) 2011 Salgado et al; licensee BioMed Central Ltd. This is an Open Access article distributed under the terms of the Creative Commons Attribution License (http://creativecommons.org/licenses/by/2.0), which permits unrestricted use, distribution, and reproduction in any medium, provided the original work is properly cited. the other hand, P4 inhibits epithelial proliferation and stimulates the multiplication of endometrial stromal cells $[2,3]$. Estrogen receptors (ER) and PR are transcription factors that regulate gene expression by direct binding to DNA regulatory sequences or by specific interactions with co-activators and/or co-repressor proteins $[4,5]$. It has been previously demonstrated that the uterus of ER $\alpha$ knock-out mice is hypoplastic, the endometrial stroma is disorganized, and the luminal epithelium is formed by cuboidal cells, which are unable to acquire a tall columnar phenotype [6]. PR knock-out mice showed that P4 is a crucial regulator of reproductive functions, as these animals are unable to ovulate, present uterine dysfunction, and altered endothelial and smooth muscle cell proliferation [7]. Moreover, our group showed a clear compartmentalization in the expression of estrogen receptors in the mouse uterine tissues [8]. 
Among the striking effects promoted by ovarian steroid hormone in the uterine tissues, we emphasize the remodeling of extracellular matrix (ECM) molecules. The ECM is a complex structure of secreted macromolecules, immobilized in the extracellular space, and composed predominantly of collagens, non-collagenous multiadhesive glycoproteins, elastin, hyaluronan and proteoglycans [9].

Decorin, biglycan, lumican and fibromodulin are members of the family of small leucine-rich-proteoglycans (SLRPs) of the ECM [10,11]. The SLRP family comprises about seventeen genes that share structural homologies, such as cysteine residues, leucine rich repeats and at least one glycosaminoglycan side chain. These proteoglycans are divided into five distinct classes. Decorin and biglycan belong to class I, presenting similarities in their amino acid sequence, in the chondroitin or dermatan sulfate side chains and a typical cluster of cysteine residues at the $\mathrm{N}$-terminus that form two disulfide bonds. Fibromodulin and lumican belong to class II, both presenting keratan sulfate and polylactosamine side chains, as well as clusters of tyrosine-sulfate residues at their $\mathrm{N}$-termini [12].

Some SLRPs act as a growth factor reservoir in the ECM, modulating biological processes, such as cell proliferation and differentiation [10,13]. They are capable of inducing signaling cascades through tyrosine kinase, tolllike and TGF- $\beta$ /BMP receptors [12]. There is strong evidence that collagen fibril-associated decorin is able to arrest TGF- $\beta$ in the ECM, inhibiting its proliferative activity [14]. Biglycan, on the other hand, has been related to the activity of BMPs in the control of embryo development [15]. In addition, these molecules also participate in the process of collagen fibrillogenesis [10]. The orientation and aggregation of collagen fibrils is partly determined by proteoglycans, as they form interfibrillar bridges [16]. Lumican and fibromodulin, for instance, are known to compete in vitro for the same attachment sites at the collagen fibril, hindering fibrillar lateral growth $[13,17,18]$.

It is known that the endometrial ECM plays important roles in decidualization, embryo implantation and trophoblast cell invasion [19]. For that purpose the endometrium must undergo complex cycles of ECM breakdown and re-arrangement, through coordinated synthesis, deposition and cleavage of its molecules.

Considering the actions of ovarian hormones in the remodeling of uterine tissues, it is reasonable to indicate that proteoglycans are modulated in the uterine ECM by these steroid hormones, whose levels fluctuate constantly in the non-pregnant and pregnant endometrium. Confirming this hypothesis our group has demonstrated that versican expression and deposition are under hormonal control in the mouse uterine tissues [20]. P4 stimulates versican deposition in the endometrium, whereas the myometrium responds exclusively to E2, evidencing that the changes observed in the cellular and ECM organization of the uterine tissues require exposure to a defined hormonal regimen.

We have previously shown the differential distribution of these SLRPs in the mouse endometrium (stroma and epithelia) and myometrium during the estrous cycle [21] and the early stages of pregnancy [22]. In this context, the aim of this study is to characterize the effects of E2 and/or medroxiprogesterone acetate (MPA) treatment on the expression and distribution of decorin, biglycan, lumican and fibromodulin in the uterine tissues of ovariectomized mice.

\section{Methods}

\section{Animals and tissue collection}

Swiss female mice, aged 3-5 months, were used in this study. Animals were housed in a 12-h light: 12-h dark, temperature-controlled $\left(22^{\circ} \mathrm{C}\right)$ environment, with free access to food and water. The stages of the estrous cycle were determined by vaginal smears. Animals in estrus and diestrus (physiological control of E2 and P4 levels, respectively), and ovariectomized animals submitted or not to hormone treatment were anesthetized with an intraperitoneal injection of tribromoethanol (Avertin ${ }^{\circledR}$ ) (Aldrich Chemical Company, Inc., Milwaukee, Wi, USA; $0,025 \mathrm{~mL} / \mathrm{g}$ body weight). The uteri were subsequently removed, cut with razor blades and immediately immersed in a fixative solution or in RNAlater solution (Sigma-Aldrich, St. Louis, MO, USA). National guidelines for laboratory animal care were followed, and all experiments were approved by the Institute of Biomedical Sciences Animal Ethics Committee (authorization number, 144/2002).

\section{Ovariectomy and hormone replacement}

The general protocol adopted by us [23] was adapted from Domino and Hurd [24]. During standardization of this experimental protocol, the established doses were $10 \mu \mathrm{g}$ of $17 \beta$-estradiol (Sigma-Aldrich) and $0.5 \mathrm{mg}$ of medroxyprogesterone acetate (MPA) (Pharmacia \& Upjohn), a progesterone analog. The choice was based on vaginal smear features and uterine morphology, which were similar to what was observed in the cycling mice [21]. Mice were ovariectomized and divided into five experimental groups, as follows:

1. Tissue collection twenty days after ovariectomy without hormone treatment.

2. Pre-treatment with daily priming doses of E2, diluted in mineral oil (Schering-Plough), for three days, followed by a two-day rest and daily injections of E2 during four consecutive days. 
3. Pre-treatment with daily priming doses of E2, followed by a resting period and daily injections of MPA, diluted in distilled water, during four consecutive days.

4. Same pre-treatment and resting period as the previous groups, followed by daily injections of both E2 and MPA during four consecutive days.

5. Control group received injections of vehicle alone (mineral oil) for three days, followed by a two-day rest and daily oil injections during four consecutive days.

All injections were sub-cutaneous in a $100 \mu$ volume. Twenty four hours after the last injection, the mice were anesthetized and the uterine samples were collected as described above.

\section{Light microscopy processing}

The samples were fixed at $4^{\circ} \mathrm{C}$ for $3 \mathrm{~h}$ in Methacarn (absolute methanol, chloroform and glacial acetic acid; $6: 3: 1$ ), rinsed with absolute ethanol, and embedded in Paraplast (Oxford, St. Louis, MO, USA) at $60^{\circ} \mathrm{C} .5 \mu \mathrm{m}$ sections were adhered onto glass slides pre-coated with $0.1 \%$ poly-L-lysine (Sigma, St. Louis, MO, USA) and then dried at $37^{\circ} \mathrm{C}$.

\section{Immunoperoxidase procedure}

The immunoperoxidase staining was performed as previously described [21]. Sections were treated with $3 \%(\mathrm{v} / \mathrm{v})$ $\mathrm{H}_{2} \mathrm{O}_{2}$ in PBS (30 min) to block endogenous peroxidase activity. Each of the succeeding steps was followed by a thorough rinse in PBS. All steps were performed in a humidified chamber. Samples were pretreated with Chondroitinase ABC from Proteus vulgaris (Seikagaku, Tokyo, Japan), diluted in $20 \mathrm{mM}$ pH 6,0 Tris- $\mathrm{HCl}$ buffer $(1 \mathrm{~h}$ at $37^{\circ} \mathrm{C}$ ). Nonspecific staining was blocked by incubating the sections for $1 \mathrm{~h}$ with normal rabbit serum (for lumican) or goat serum (for the other molecules), diluted 1:1 (v/v) in PBS - 10\% BSA (w/v) (room temperature). Sections were then incubated with primary antibodies (Table 1) diluted in PBS containing $0.3 \%(\mathrm{v} / \mathrm{v})$ Tween 20 , overnight $\left(4^{\circ} \mathrm{C}\right)$. After extensive rinsing in PBS all sections were incubated

\section{Table 1 Antibodies}

\begin{tabular}{|c|c|c|c|}
\hline Primary Ab & [ ] & $\begin{array}{l}\text { Second Ab - Biotin Conjugated } \\
\text { (Rockland\$) }\end{array}$ & [ ] \\
\hline $\begin{array}{l}\text { Anti-decorin } \\
(\mathrm{LF}-113 \infty)\end{array}$ & $1: 3000$ & $\begin{array}{l}\text { Anti-rabbit } \\
\text { (goat) }\end{array}$ & $1: 2000$ \\
\hline 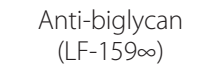 & $1: 1000$ & $\begin{array}{l}\text { Anti-rabbit } \\
\text { (goat) }\end{array}$ & $1: 2000$ \\
\hline $\begin{array}{l}\text { Anti-lumican } \\
\text { (R\&D Systems } ¥)\end{array}$ & $1: 1500$ & $\begin{array}{l}\text { Anti-goat } \\
\text { (rabbit) }\end{array}$ & $1: 2000$ \\
\hline 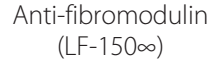 & 1:400 & $\begin{array}{l}\text { Anti-rabbit } \\
\text { (goat) }\end{array}$ & $1: 2000$ \\
\hline
\end{tabular}

$\infty$ Dr. Larry Fisher (National Institute of Dental and Craniofacial Research, NIH, Bethesda, MD).

$¥$ R\&D Systems - Minneapolis, MN, USA.

$\S$ Rockland - Gilbertsville, PA, USA. for $1 \mathrm{~h}$ at room temperature with the specific biotinconjugated secondary antibody (Table 1) diluted in PBS, for $1 \mathrm{~h}$ at room temperature. After rinsing in PBS, sections were incubated with Vectastain ABC kit (Vector Laboratories, Burlingame, CA, USA) for $1 \mathrm{~h}$ at room temperature. The peroxidase reaction was visualized using $0.03 \%(\mathrm{w} / \mathrm{v})$ 3,3'-diaminobenzidine in PBS with $0.03 \%(\mathrm{v} / \mathrm{v}) \mathrm{H}_{2} \mathrm{O}_{2}$. In order to achieve standardization of the immunoreactions, for each antibody, the slides were simultaneously incubated with $D A B$, and reaction was immediately interrupted with PBS after a specific period of time (1-5 minutes, depending on the antibody). Afterwards, sections were lightly counterstained with Mayer's haematoxilin (Merck, Darmstadt, Germany). For each immunohistochemical reaction, control reactions were performed by omitting the primary antibody step from the protocol. In addition, paraffin sections of mouse embryos were used as positive and negative control.

The immunostained sections were examined in a Nikon Eclipse E600 microscope and the images were captured using a digital camera (Cool SNAP-Procf color; Roper Scientific, Trenton, NJ, USA) and Image Pro Plus software (Media Cybernetics, Silver Spring, MD, USA).

\section{Antibodies}

Table 1 lists the antibodies used in the present study. Decorin, biglycan and fibromodulin antibodies (LF-113, LF-159 and LF-150, respectively) were raised in rabbit and recognize the core protein of each macromolecule. These antibodies were previously tested by Western blot by the producers. Detail of the procedures made by Larry Fisher (National Institute of Dental and Craniofacial Research, $\mathrm{NIH}$, Bethesda, USA) may be found in Fisher et al [23].

The anti-mouse lumican antibody (R\&D Systems, \#AF2745) is an IgG produced in goats, immunized with purified, NS0-derived, recombinant mouse Lumican (rmLumican). The mouse lumican specific IgG was purified by affinity chromatography. The specificity was tested by direct ELISA and Western blot.

\section{mRNA extraction and real-time PCR}

For the molecular biology experiments, the phases of estrus (highest estrogen levels) and diestrus (highest progesterone levels) were chosen to represent the estrous cycle.

Upon use, uterine samples ( $\mathrm{n}=6$ per group), excised with sterilized razor blades and stored in RNAlater solution at $-20^{\circ} \mathrm{C}$, were transferred to sterile microfuge tubes containing ceramic beads and $500 \mu \mathrm{l}$ of Trizol reagent (Invitrogen, Calbard, CA, USA). Samples were homogenized and total RNA extracted using the Precellys 24 homogenizer (Bertin Technologies, Saint-Quentin-en-Yvelines, France), following the manufacturer's instructions. RNA quantity and quality were assessed with a NanoDrop spectrophotometer 
(Thermo Fisher Scientific Inc., USA). Reverse transcription (RT-PCR) was performed with AffinityScript QPCR cDNA Synthesis kit (Stratagene, Cedar Creek, TX, USA) and $1 \mu \mathrm{g}$ of total RNA. Different reference genes were tested and Ywhaz (Tyrosine 3-monooxygenase/tryptophan 5-monooxygenase activation protein, zeta polypeptide) was chosen as internal control for showing the most uniform expression across groups in the PCR amplification experiments. The relative expression of the SLRPs mRNA was determined as described previously [25]. The relative levels of mRNA of the tested genes were estimated in duplicate samples by fluorescence quantified with the ABI Prism 7500 sequence detector (Applied Biosystems, Ontario, Canada). Reactions were performed in a total volume of $25 \mu$ l containing $20 \mathrm{ng}$ of cDNA and $450 \mathrm{nM}$ primers in a reaction buffer containing SYBR Green PCR master mix (Stratagene). All $C_{\mathrm{q}}$ (quantification cycle, according to the MIQE guidelines [26]) values were normalized to the expression of the reference gene and the results were expressed as fold-induction relative to the expression of the calibrator sample (estrus), arbitrarily set to 1 . Primers were designed with NCBI's primer designing tool to span an exon-exon junction, in order to limit amplification only to mRNA. Primer sequences are given in Table 2.

\section{Statistical analysis}

Multiple comparisons were performed by one-way analysis of variance (ANOVA) followed by the Student Newman Keuls post-test to determine significant differences among all groups, using Prism 4.0 (GraphPad Software, San Diego, CA, USA). All results are expressed as the mean \pm standard error of the mean (SEM). Values of $p$ less than or equal to 0.05 were considered statistically significant.

\section{Results}

Two morphologically distinct compartments can be identified in the endometrial stroma, herein denoted as superficial and deep stroma; in the myometrium, three distinct layers are observed, denominated internal muscle layer, external muscle layer and connective tissue between layers or vascular plexus $[21,20]$.

\section{Decorin immunolocalization}

Ovariectomy did not suppress the deposition of decorin in the uterine tissues. In the non-treated groups (ovx and oil), the immunoreaction was present in the deep stroma and only traces were observed in the superficial stroma. In the myometrium, the immunoreaction was present in the external muscle layer (EML) and connective tissue between layers, but was not observed in the ECM of the internal muscle layer (IML) (Figure 1A).

In the E2-treated group, strong immunoreaction was present in the whole endometrial stroma, observed as a network of thin brownish filaments. The immunoreaction was more intense around the luminal and glandular epithelia, as well as around blood vessels. The staining was also strong in the myometrium, especially around bundles of smooth muscle cells in the EML (Figure 1B).

In the MPA-treated group, the immunoreaction was strong in the deep stroma, however only traces were observed in the subepithelial stroma, as previously observed in diestrus [20]. In the myometrium, the reaction was present in the ECM and inside muscle cells of both layers, and in the connective tissue between layers (Figure 1C).

In the E2+MPA-treated group, the immunoreaction was present in the whole stroma, as a network of thin filaments, except in the subepithelial stroma at the cleft regions of the luminal epithelium branches. In the myometrium, the immunostaining was moderate in the ECM of the IML and strong in the EML and connective tissue between layers (Figure 1D).

\section{Relative expression of decorin mRNA}

During the estrous cycle, there were no significant differences between groups. Ovariectomy significantly increased decorin mRNA expression $(\approx 4$ fold) $(\mathrm{p}<0.001)$ when compared to estrus. Hormone replacement promoted a significant reduction in decorin expression in the E2-treated group $(\approx 4$ fold) $(\mathrm{p}<0.001)$ and MPA and E2 + MPA-treated groups $(\approx 2$ fold $)(\mathrm{p}<0.01)$, when compared to the non-treated ovariectomized group. Moreover, decorin expression in the MPA and E2+MPA-treated groups

Table 2 Mouse oligonucleotide primers $\left(5^{\prime} \rightarrow 3^{\prime}\right)$

\begin{tabular}{|c|c|c|c|}
\hline Gene & Forward (F) and Reverse (R) primers & Amplicon size & Genbank \# \\
\hline Decorin & $\begin{array}{l}\text { F: TGCGATCCCTCAAGGTCTGCCT } \\
\text { R: TTGGCCAGACTGCCATTCTCCA }\end{array}$ & 162 bp & NM_007833.4 \\
\hline Biglycan & $\begin{array}{l}\text { F: AGGAGGCTTCAGGTTCAG } \\
\text { R: TAGCAGTGTGGTGTCAGG }\end{array}$ & 171 bp & NM_007542 \\
\hline Lumican & $\begin{array}{l}\text { F: CATTAGTCGGTAGTGTCAGTG } \\
\text { R: TGCCAGGAGGAACCATTG }\end{array}$ & $171 \mathrm{bp}$ & NM_008524 \\
\hline Fibromodulin & $\begin{array}{l}\text { F: TGCCACATTCTCCAACCCAAGG } \\
\text { R: GAGCAGAGCCCAGCCAGCAG }\end{array}$ & 116 bp & NM_021355.3 \\
\hline Ywhaz & $\begin{array}{l}\text { F: GAAGCCACAATGTTCTTGGCCCAT } \\
\text { R: AAACCAACAGAGACTTGGAAGCAC }\end{array}$ & $84 \mathrm{bp}$ & NM_011740.2 \\
\hline
\end{tabular}




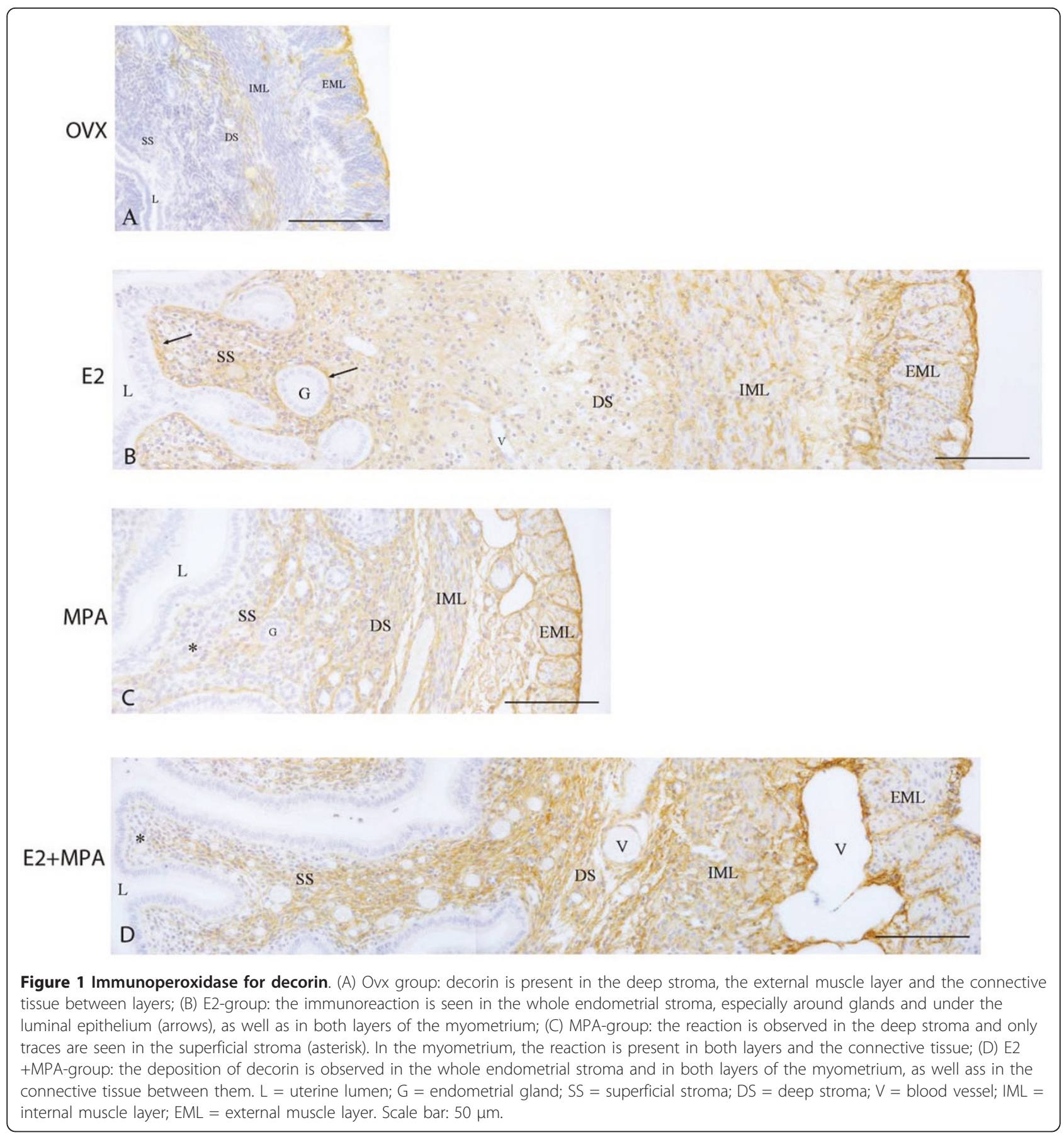

was significantly higher than in diestrus and estrus, respectively $(\approx 2$ fold) $(\mathrm{p}<0.01)$ (Figure 2$)$.

\section{Biglycan immunolocalization}

In the ovx and oil groups, the deposition of biglycan was not observed in the endometrium and myometrium. However, the immunoreaction was detected in the cytoplasm of mononucleated leukocytes (Figure 3A).
In the E2-treated group, the immunoreaction was present in the endometrial stroma mainly around the luminal and glandular epithelia. In the myometrium, the staining was observed in the ECM of both smooth muscle layers, especially the IML, and in the connective tissue between them, particularly around blood vessels (Figure 3B).

In the MPA-treated group, a diffuse brownish staining was observed in the endometrial stroma. In the myometrium, 


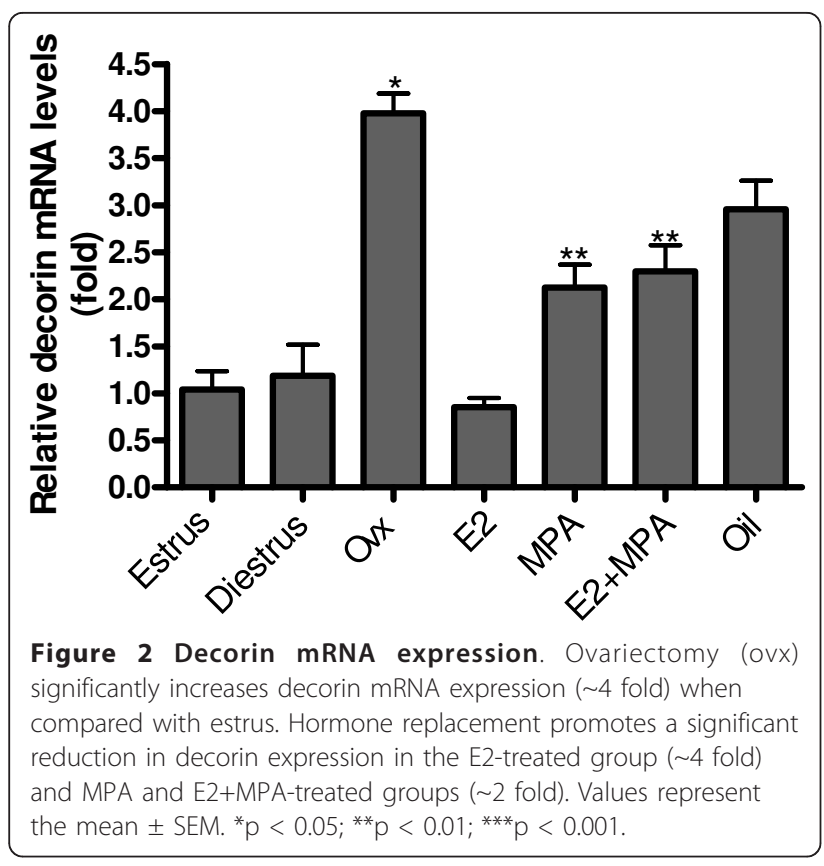

the immunoreaction was moderate in both layers. It was also present in the connective tissue between layers, especially around blood vessels (Figure 3C).

In the E2+MPA-treated group, biglycan was distributed as a network of thin brownish filaments, especially in the subepithelial stroma, where leukocytic infiltration was observed. In the myometrium, the immunoreaction was more conspicuous in the IML and connective tissue between layers, whereas a weak staining was observed in the EML (Figure 3D).

\section{Relative expression of biglycan mRNA}

As observed for decorin, there was no significant difference in biglycan mRNA levels between estrus and diestrus. However, after ovariectomy there was a drastic reduction in biglycan expression $(\approx 3$ fold $)(\mathrm{p}<0.001)$, when compared to estrus. A significant increase was observed after hormone treatment with MPA $(\approx 3$ fold $)$ ( $\mathrm{p}<0.05)$ and E2+MPA $(\approx 5$ fold $)(\mathrm{p}<0.001)$, when compared to the non-treated ovariectomized group. Treatment with E2 alone did not promote significant differences in biglycan mRNA levels in relation to the ovariectomized group. However, it was significantly lower than in estrus $(\approx 2$ fold $)(\mathrm{p}<0.05)$ (Figure 4$)$.

\section{Lumican immunolocalization}

In the ovx and oil groups, a faint immunoreaction was observed in the scarce extracellular spaces of the endometrial stroma, especially in the region of basement membrane of the luminal epithelium, as well as in the deep stroma. In the myometrium, the deposition of lumican was weak in the connective tissue between layers, in the EML and in the outer lining of the uterus, the mesothelium (Figure 5A).

In the E2-treated group, lumican was widely distributed in the whole endometrial stroma, in both layers of the myometrium, around bundles of smooth muscle cells, and in the connective tissue between layers (Figure 5B).

In the MPA-treated group, the immunoreaction was present in the whole endometrial stroma as a diffuse brownish staining, particularly in the deep stroma. Under the luminal epithelium, only traces of immunoreaction were observed. In the myometrium, the immunostaining was present only in the EML and connective tissue between layers (Figure $5 \mathrm{C}$ ).

In the E2+MPA-treated group, strong immunoreaction was present in the whole endometrial stroma. In the myometrium, the immunodeposition of lumican was observed in the connective tissue between layers and a weak staining was present in both myometrial layers, especially in the EML (Figure 5D).

\section{Relative expression of lumican mRNA}

There were no significant differences in lumican expression between estrus and diestrus. After ovariectomy there was $\mathrm{a} \approx 2$ fold increase in lumican mRNA levels when compared to estrus. Hormone treatments did not significantly alter lumican expression in the uterus, when compared to the non-treated ovariectomized group, maintaining a $\approx 2$ fold increase in relation to estrus $(\mathrm{p}<0.05)$ (Figure 6).

\section{Fibromodulin immunolocalization}

In the ovx and oil groups, fibromodulin immunostaining was not observed in the ECM of the endometrium and myometrium. However, some mononucleated leukocytes were immunoreactive in the endometrial stroma, as previously observed during the estrous cycle (Figure 7A).

In the E2-treated group, the immunoreaction was present in the apical region of the luminal epithelium and in the cytoplasm of mononucleated leukocytes observed in the endometrial stroma. Strong immunostaining was present in both myometrial layers, and around blood vessels of the connective tissue between layers (Figure 7B).

In the MPA-treated group, the immunoreaction was present in the luminal epithelium. The glandular secretion was also immunoreactive to fibromodulin. In the myometrium, the immunoreaction was strong in both muscle layers, particularly the EML (Figure 7C).

In the E2+MPA-treated group, the staining pattern was similar to that observed in the MPA group (Figure 7D).

\section{Relative expression of fibromodulin mRNA}

Fibromodulin mRNA expression was significantly higher in diestrus than in estrus $(\approx 2$ fold $)(p<0.05)$. Ovariectomy promoted a conspicuous increase in fibromodulin mRNA 


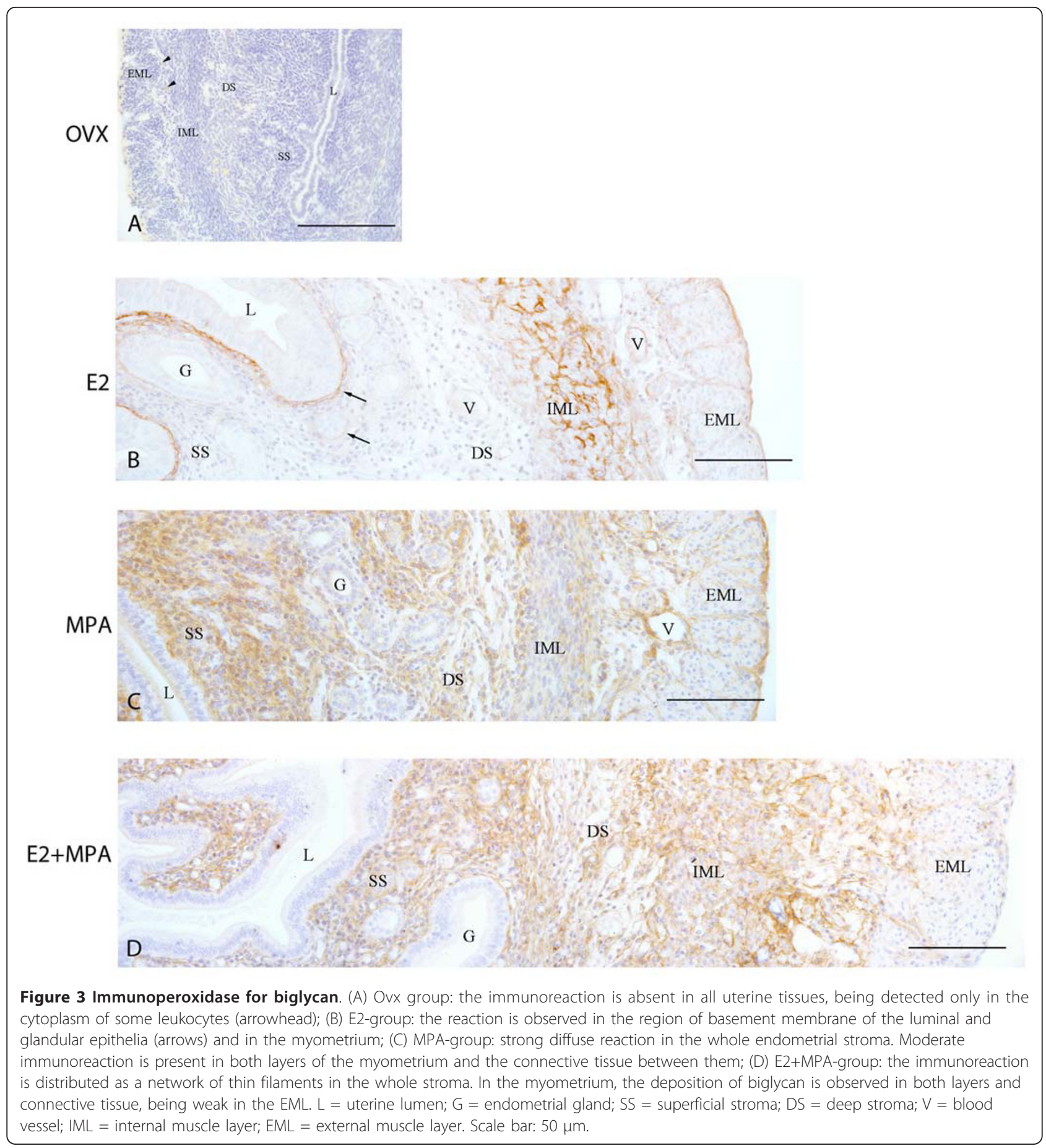

levels, when compared to estrus $(\approx 7$ fold $)$ ( $p<0.001)$. In addition, fibromodulin expression was significantly reduced after E2 treatment $(\approx 7.5$ fold) $(\mathrm{p}<0.001)$, when compared to the non-treated ovariectomized group. Moreover, MPA and E2+MPA groups showed significantly augmented expression when compared to diestrus $(\approx 2$ fold $)(\mathrm{p}<0.01)$ and estrus $(\approx 2.5$ fold $)(\mathrm{p}<0.05)$, respectively (Figure 8$)$.

\section{Discussion}

It is well established that in rodents the endometrium provides a unique environment, which allows or prevents embryo implantation. It is also known that the endometrium undergoes dynamic reorganization during the estrous cycle in preparation for these important events [27]. Concerning the extracellular matrix, previous studies 


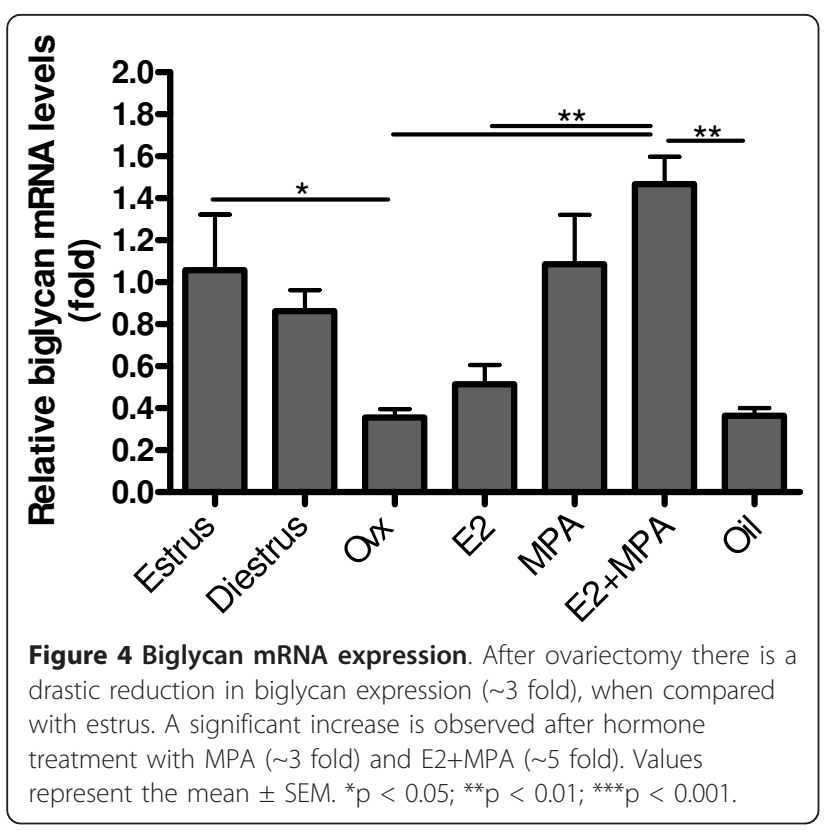

from our group described that the structure and composition of ECM molecules in the distinct uterine tissues is affected throughout the phases of the estrous cycle $[21,20,28]$.

In this study, the expression and distribution of decorin, biglycan, lumican and fibromodulin in the endometrium and myometrium were found to be ovarian hormone-dependent and dose-related, evidencing that those molecules play important roles in the preparation for embryo implantation and successful gestation. Previously, San Martin et al [22] showed that decorin and lumican are present in the superficial stroma on day four of pregnancy, before decidualization. However, decorin disappears from the endometrial stroma, following a progesterone peak and the establishment of the decidua. Interestingly, decorin is absent and lumican deposition is reduced in the superficial stroma in the diestrus phase [21], characterized by high levels of progesterone [29]. Coherently, the present results showed a similar distribution pattern after MPA treatment.

The loss of decorin and reduction of lumican in this context is functionally relevant, as both have anti-proliferative activity $[30,31]$, and in the beginning of decidualization there is considerable DNA synthesis and cell proliferation under strict hormonal control [32,33]. Moreover, decorin is known for its tumor-suppressive role. $\mathrm{Hu}$ et al [34] demonstrated that decorin is able to suppress prostate tumor growth through inhibition of the EGFR signaling pathway. Additionally, Gu et al [35] showed that decorin gene expression is down-regulated in mammary tumor tissue when compared to normal mammary gland tissue. Thus, our data suggest that P4 is capable of inhibiting or reducing, directly or through other regulatory molecules, the expression and deposition of decorin in the superficial stroma, while stimulating the opposite effect in the deep stroma, which corroborate high cell proliferation rate in the superficial stroma (unpublished data) and the existence of two genetically distinct subpopulations of endometrial fibroblasts.

This proliferative phenomenon modulated by ECM molecules is important for the preparation of the superficial stroma to decidualize, while maintaining an undifferentiated layer of endometrial fibroblasts in the deep stroma, which is associated with reconstruction of the endometrium in the post-partum period [36]. In addition, these results reinforce the existence of distinct functional compartments of the mouse endometrium, similar to the organization into basal and functional layers of the human endometrium.

Moreover, the SLRPs studied herein are known to regulate collagen fibrillogenesis. Decorin is considered a regulatory molecule, delaying the thickening of collagen fibrils $[17,37]$. This study from Vogel and Trotter [37] demonstrated that decorin, as well as lumican, link to fibrillar collagens in vitro, stabilizing thin fibrils. Ameye et al [38] showed that fibromodulin-deficient mice synthesize abnormal and less numerous fibril bundles, and these fibrils are often irregular and their diameter is decreased. Decorin knock-out mice present irregular fibrils with increased diameter in the endometrial stroma of the pregnant mouse uterus. In addition, there is an augment in lumican deposition in the endometrial ECM of decorin-deficient mice, when compared to wildtype littermate, demonstrating that both SLRPs compensate each other's expression in abnormal situations [39]. During early pregnancy in wild-type mice, the loss of decorin, reduction of lumican and the deposition of biglycan in the decidual ECM are related to the appearance of thick collagen fibrils in the mature and pre-decidua [21]. The only reports on the presence of lumican in the uterus are part of previous studies from our group $[21,22,39]$ and the influence of ovarian hormones on its expression in the uterus was uncertain until now. It is known that lumican knock-out mice are viable, but present reduced body weight and their litter are considerably smaller, suggesting the relevance of this proteoglycan for proper fetal growth [40].

A recent report by Markiewicz et al. [41] describes a significant decrease in lumican, decorin and fibromodulin mRNA levels in the skin of ovariectomized mice, when compared to wild-type littermate. Contrarily, our results showed that withdrawal of ovarian hormones through ovariectomy promotes an augment in decorin, lumican and fibromodulin mRNA expression in the mouse uterus, and that E2 replacement induces a significant decrease in their mRNA levels. Indeed, microarray 


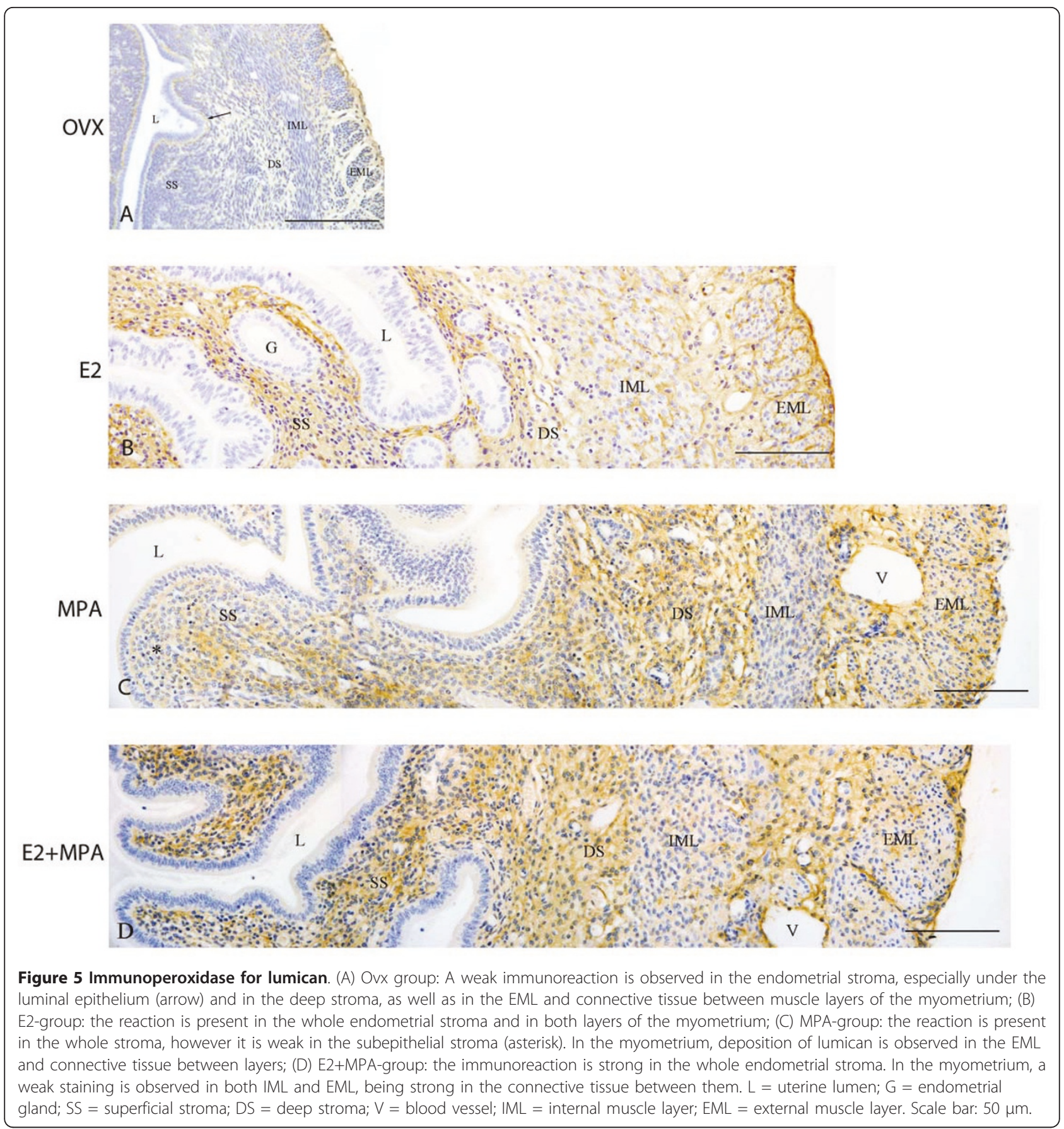

data has previously demonstrated that decorin and fibromodulin expression is down-regulated by E2 treatment in the uterus of ovariectomized mice, corroborating our findings [42].

Despite the lack of deposition of both biglycan and fibromodulin in the ECM of the endometrium and myometrium in the ovx group, it is clear that withdrawal of ovarian hormones promotes opposite effects on their mRNA expression. Biglycan mRNA levels decreased, whereas fibromodulin mRNA levels conspicuously increased, suggesting that distinct post-transcriptional modifications may occur among closely related molecules. In fact, mature mRNA transcripts may be modified by different reactions, such as alternative transcription start sites, alternative splicing and alternative polyadenylation site selection [43].

In the human myometrium, fibromodulin expression is significantly higher in the secretory phase (progesterone dominance) than in the proliferative phase (estrogenic dominance) of the menstrual cycle [44]. We demonstrated 


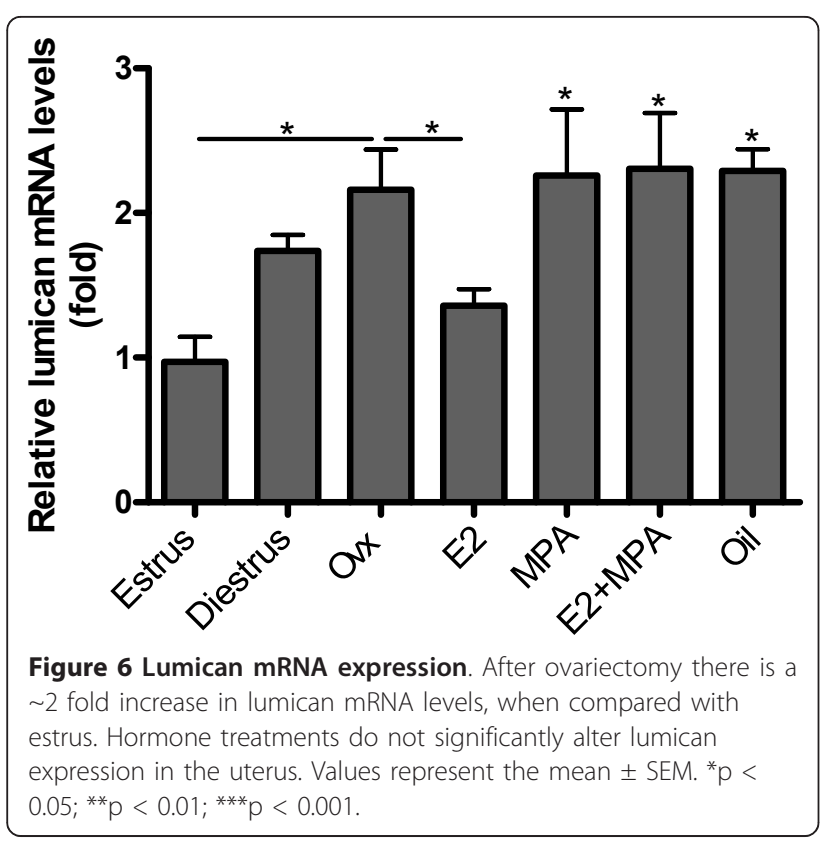

that, after hormone treatments, fibromodulin deposition was strong in the myometrial ECM, as observed during the estrous cycle and the early stages of pregnancy, which suggests that fibromodulin acts in a hormone-dependent manner in the remodeling of the myometrium. The present findings also showed that deposition of all four SLRPs was abolished from the internal and external layers of the myometrium after ovariectomy, evidencing that this uterine compartment is highly sensitive to fluctuations in ovarian hormone levels.

Curiously, only biglycan and fibromodulin were detected in the cytoplasm of uterine epithelial cells during the estrous cycle and after hormone replacement. Schaefer et al [45] showed the deposition of biglycan in glomerular endothelial cells of renal tubules, whereas Qian et al [46] demonstrated that fibromodulin is expressed in gingival epithelium, indicating that epithelial cells synthesize and secrete those proteoglycans in the ECM and/or act in tissue remodeling through internalization of secreted molecules. Biglycan is a wellknown proteoglycan of pericellular matrices [12] and modulates cell signaling events. Only in the E2-treated group, biglycan was deposited preferentially in the region of epithelial basement membrane and around blood vessels, suggesting that its deposition is regulated by E2 in a dose-dependent manner.

Hormone actions on target cells involve complex molecular mechanisms. In our model, this complexity may be exacerbated through the activity of metalloproteinases and growth factors, such as TGF- $\beta$. The glycosaminoglycan side chains attached to the proteoglycan molecule possibly create a permissive environment for the accumulation of growth factors in the ECM, thus modulating cell metabolism.

Studies by Kim at al [47] showed that, in women, after hormonal stimulus by E2 and P4, TGF $\beta$ expression is upregulated in the endometrium, being down-regulated after P4 withdrawal. Unpublished data from our group showed that TGF $\beta$ is widely distributed in the mouse endometrial stroma in the phases of estrus and diestrus. A previous report showed that TGF $\beta 1,2$ and 3 are expressed in mouse uterine tissues during early pregnancy [48]. Additionally, P4 is capable of inducing the expression of TGF $\beta 1$ by uterine epithelial cells and stromal fibroblasts [47]. It is known that SLRPs modulate TGF $\beta$ activity in the uterine stroma and other tissues, controlling important biological processes, such as cell proliferation and apoptosis $[12,49]$. It should be considered, however, that the regulation of cellular responses to growth factors depends not only on the presence, but also on the concentration of these molecules in the tissues.

Additionally, it is important to acknowledge the role of specific proteases in this modulation process. For instance, a previous report by Monfort et al [50] described that decorin, lumican, biglycan and fibromodulin are cleaved by metalloproteinase 13 (MMP-13) in cartilage, at specific aminoacid sequences and at distinct rates. Imai et al [51] showed that decorin is cleaved, at different sites, by MMPs 2, 7 and especially MMP 3, a well known proteoglycanase of many tissues. The controlled cleavage of decorin is related to TGF- $\beta$ release in the ECM. Thus, MMPs may exert distinct actions under specific hormonal influence. These molecules may also generate bioactive peptides that play key roles in tissue remodeling. Indeed, versican, an aggregating proteoglycan widely distributed in the mouse endometrium, is cleaved by ADAMTS, generating specific peptides that most likely participate in biological processes, such as cell migration, proliferation, and differentiation [52].

Another important variable in the context of steroid hormone action is the regulation of mRNA stability of several molecules, as well as the activity of RNases [53-55]. Small RNA species, such as microRNAs and small interference RNAs, are known to regulate gene expression in a posttranscriptional way through cleavage of the target mRNA or translational repression [56]. Steroid hormones, such as testosterone, have been identified as potential modulators of small RNA activity [57]. Moreover, the half-life of different RNA species is important to determine the length of time in which these mRNA molecules will act as template for protein translation. For instance, Saceda et al [58] showed that $\mathrm{P} 4$ promotes the increase in the half-life of its own receptor's mRNA from six to twelve hours, in primary cell culture of endometrial fibroblasts. Presently, studies are being developed in our laboratory to determine 


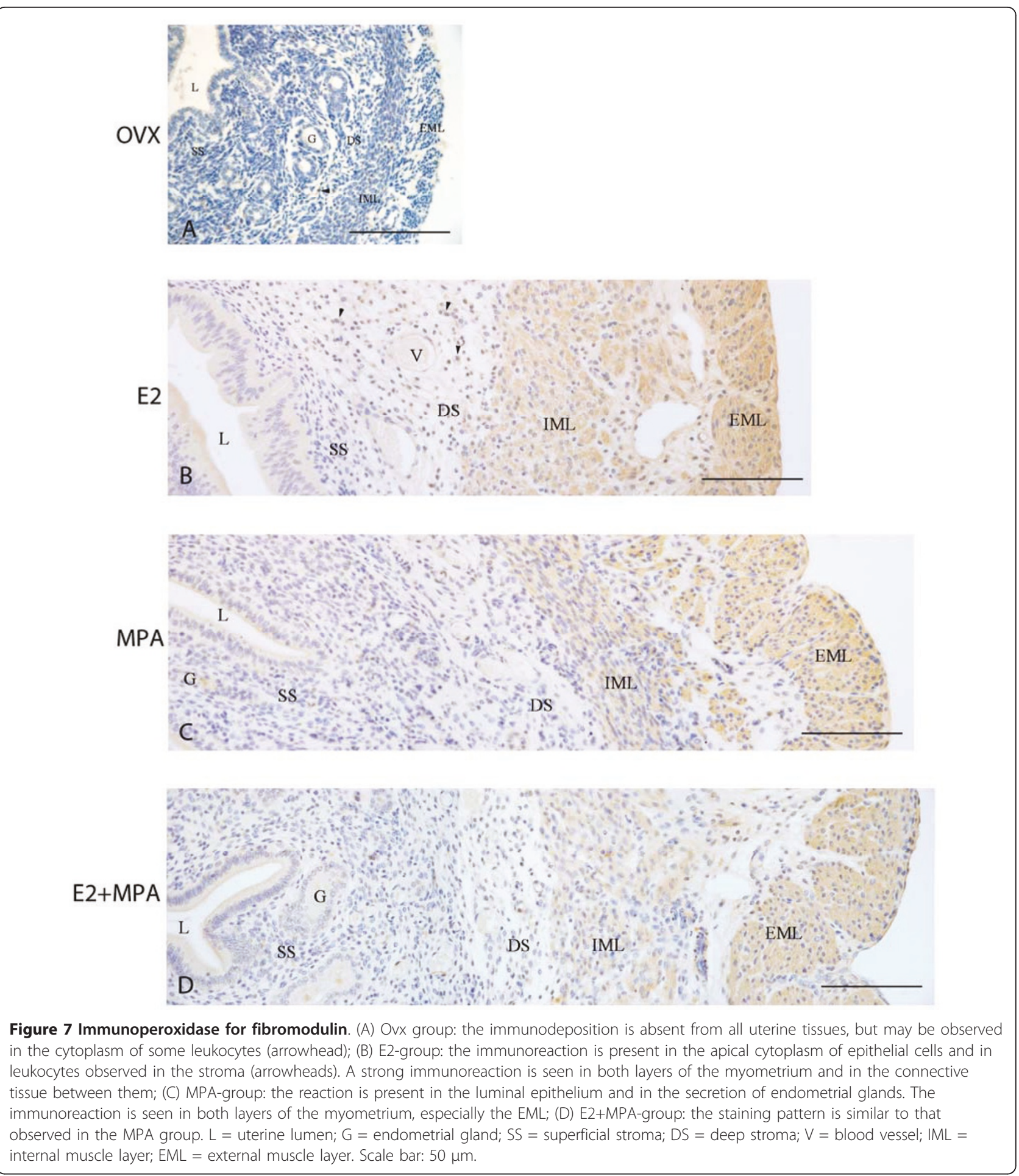

whether E2 and P4 alter the mRNA stability of secreted proteoglycans of the mouse uterus.

\section{Conclusions}

This and a previous study from our group suggest that hormonal regulation of mRNA splicing, transcription and post-transcriptional modifications, protein deposition in the ECM, and regulation of metalloproteinases are important events to be considered when studying the differential expression of ECM components, as well as tissue remodeling, in the reproductive organs during the sexual cycle and pregnancy. 


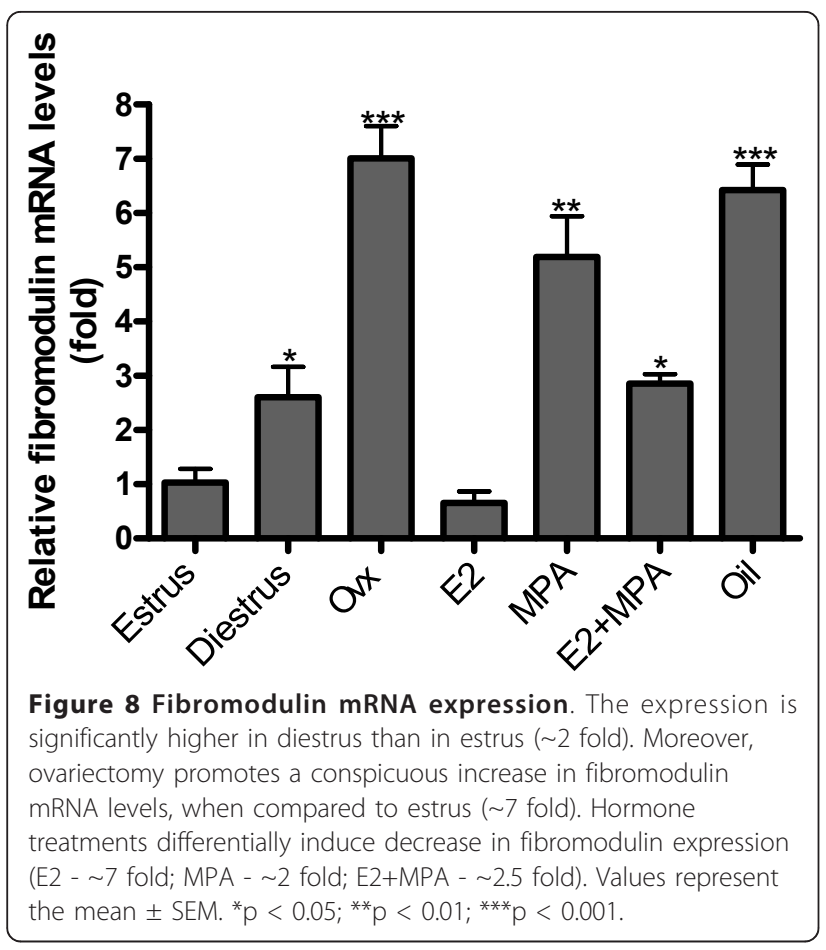

\section{Acknowledgements}

This study was carried out as partial fulfillment of a PhD degree by Renato M Salgado (advisor: TMT Zorn) and was supported by a fellowship from FAPESP (04/09947-2) and grants from FAPESP, CAPES and CNPq. The authors are grateful to Dr. Larry Fisher for granting them with anti-decorin, antibiglycan and anti-fibromodulin antibodies. We are thankful to Mrs. Fernanda Barrence, Mrs. Cleusa Pellegrino, Mrs. Tatiana Fonseca, Mrs Juliane Sanches and Dr. Karin Spiess for the excellent technical assistance. We thank Dr. Sebastian San Martin for the preliminary studies with hormone treatment and SLRPs in the mouse uterus. We also thank Dr. Alison Colquhoun for the language review.

\section{Authors' contributions}

RS carried out the collection and preparation of samples, the staining procedures, the molecular biology experiments and drafted the manuscript. RF participated in the light microscopy experiments, has made substantial contributions to analysis and interpretation of data, and helped to draft the manuscript. TZ conceived of the study, participated in its design and coordination and helped to draft the manuscript. All authors read and approved the final manuscript.

\section{Competing interests}

The authors declare that they have no competing interests.

Received: 8 November 2010 Accepted: 4 February 2011 Published: 4 February 2011

\section{References}

1. Allen E: The oestrous cycle in the mouse. Am J Anat 1927, 30:297-371.

2. Martin L, Finn CA: Hormone secretion during early pregnancy in the mouse. J Endocrinol 1969, 45:57-65.

3. Parandoosh Z, Crombie DL, Tetzke TA, Hayes JS, Heap RB, Wang M-W: Progesterone and oestrogen receptors in the decidualized mouse uterus and effects of different types of anti-progesterone treatment. J Reprod Fertil 1995, 105:215-220.

4. Lydon JP, DeMayo FJ, Funk CR, Mani SK, Hughes AR, Montgomery CA Jr, Shyamala G, Conneely OM, O'Malley BW: Mice lacking progesterone receptor exhibit pleiotropic reproductive abnormalities. Genes Dev 1995, 9:2266-2278.

5. Weihua Z, Saji S, Sirpa M, Cheng G, Jensen EV, Warner M, Gustafsson J: Estrogen receptor (ER) $\beta$, a modulator of ERa in the uterus. Procl Natl Acad Sci USA 2000, 97:5936-5941.

6. Couse JF, Korach KS: Estrogen receptor null mice: what have we learned and where will they lead us? Endocr Rev 1999, 20(3):358-417.

7. Mulac-Jericevic B, Conneely OM: Reproductive tissue selective actions of progesterone receptors. Reproduction 2004, 128:139-146.

8. Zorn TM, Soto-Suazo M, Pellegrini CR, Oliveira JG, Stumpf WE: E2 receptor binding to the epithelium of uterine lumen and glands: region- and time-related changes during preimplantation and periimplantation periods studied by autoradiography. Histochem Cell Biol 2003, 120(1):1-12.

9. Kresse H, Schönherr E: Proteoglycans of the extracellular matrix and growth control. J Cell Physiol 2001, 189:266-274.

10. Hocking AM, Shinomura T, McQuillan DJ: Leucine-rich repeat glycoproteins of the extracellular matrix. Matrix Biol 1998, 17:1-19.

11. Iozzo RV: The biology of the small leucine-rich proteoglycans Functional network of interactive proteins. J Biol Chem 1999, 274:18843-18846.

12. Schaefer L, lozzo RV: Biological functions of the small leucine-rich proteoglycans: from genetics to signal transduction. J Biol Chem 2008, 283(31):21305-21309

13. Vogel KG, Paulsson $M$, Heinegard D: Specific inhibition of type I and type II collagen fibrilogenesis by the small proteoglycan of tendon. Biochem J 1984, 222:587-597.

14. Hildebrand A, Romarís M, Rasmussen LM, Heinegård D, Twardzik DR, Border WA, Ruoslahti E: Interaction of the small interstitial proteoglycans biglycan, decorin and fibromodulin with transforming growth factor beta. Biochem J 1994, 302(Pt 2):527-34.

15. Moreno M, Muñoz R, Aroca F, Labarca M, Brandan E, Larraín J: Biglycan is a new extracellular component of the Chordin-BMP4 signaling pathway. EMBO J 2005, 24(7):1397-1405.

16. Scott JE: Supramolecular organization of extracellular matrix glycosaminoglycans, in vitro and in the tissues. FASEB J 1992, 6:2639-2645

17. Rada JA, Cornuet PK, Hassell JR: Regulation of corneal collagen fibrillogenesis in vitro by corneal proteoglycan (lumican and decorin) core proteins. Exp Eye Res 1993, 56:635-648.

18. Svensson L, Aszódi A, Reinholt FP, Fässler R, Heinegard D, Oldberg A: Fibromodulin-null mice have abnormal collagen fibrils, tissue organization, and altered lumican deposition in tendon. J Biol Chem 1999, 274:9636-9647.

19. Aplin JD: Endometrial Extracellular Matrix. In The Endometrium. Edited by: Glasser SR, Aplin JD, Giudice LC, Tabibzadeh S. London and New York: Taylor 2002:294-307.

20. Salgado RM, Capelo LP, Favaro RR, Glazier JD, Aplin JD, Zorn TMT: Hormone-regulated expression and distribution of versican in mouse uterine tissues. Reprod Biol Endocrinol 2009, 7:60

21. Salgado RM, Favaro RR, San Martin S, Zorn TM: The estrous cycle modulates small leucine-rich proteoglycans expression in mouse uterine tissues. Anat Rec 2009, 292:138-153.

22. San Martin S, Soto-Suazo M, Ferreira de Oliveira S, Aplin JD, Abrahamsohn P, Zorn TMT: Small leucine-rich proteoglycans (SLRPs) in uterine tissues during pregnancy in mice. Reproduction 2003, 125:585-595.

23. Fisher LW, Stubbs JT, Young MF: Antisera and CDNA probes to human and certain animal model bone matrix noncollagenous proteins. Acto Orthop Scand Supp/ 1995, 266:61-65.

24. Domino SE, Hurd EA: LacZ expression in Fut2-LacZ reporter mice reveals estrogen-regulated endocervical glandular expression during estrous cycle, hormone replacement, and pregnancy. Glycobiology 2004, 14:169-175.

25. Capelo LP, Beber EH, Huang SA, Zorn TM, Bianco AC, Gouveia CH: Deiodinase-mediated thyroid hormone inactivation minimizes thyroid hormone signaling in the early development of fetal skeleton. Bone 2008, 43(5):921-930

26. Bustin SA, Benes V, Garson JA, Hellemans J, Huggett J, Kubista M, Mueller R, Nolan T, Pfaffl MW, Shipley GL, Vandesompele J, Wittwer CT: The MIQE guidelines: minimum information for publication of quantitative realtime PCR experiments. Clin Chem 2009, 55(4):611-622.

27. Rugh R: The Mouse, its Reproduction and Development. 2 edition. Oxford: Oxford Science; 1990, 7-101. 
28. Stumm CL, Zorn TM: Changes in fibrillin-1 in the endometrium during the early stages of pregnancy in mice. Cells Tissues Organs 2007, 185:258-268.

29. Wood GA, Fata JE, Watson KLM, Khokha R: Circulating hormones and estrous stage predict cellular and stromal remodeling in murine uterus. Reproduction 2007, 133:1035-1044.

30. Yamaguchi Y, Ruoslahti E: Expression of human proteoglycan in Chinese hamster ovary cells inhibits cell proliferation. Nature 1988, 336:244-246.

31. Vij N, Roberts L, Joyce $S$, Chakravarti S: Lumican suppresses cell proliferation and aids Fas - Fas ligand mediated apoptosis: implications in the cornea. Exp Eye Res 2004, 78:957-971.

32. Martin L, Finn CA: Hormonal regulation of cell division in epithelial and connective tissues of the mouse uterus. J Endocrinol 1968, 41:363-371.

33. Abrahamsohn PA, Zorn TMT: Implantation and decidualization in rodents. Journal of Exp Zool 1993, 266:603-628.

34. Hu Y, Sun H, Owens RT, Wu J, Chen YQ, Berquin IM, Perry D, O'Flaherty JT, Edwards IJ: Decorin suppresses prostate tumor growth through inhibition of epidermal growth factor and androgen receptor pathways. Neoplasia 2009, 11(10):1042-1053.

35. Gu Y, Zhang S, Wu Q, Xu S, Cui Y, Yang Z, Zhao X, Sun B: Differential expression of decorin, EGFR and cyclin D1 during mammary gland carcinogenesis in TA2 mice with spontaneous breast cancer. J Exp Clin Cancer Res 2010, 29:6.

36. Kleinfeld RG, O'Shea JD: Spatial and temporal patterns of deoxyribonucleic acid synthesis and mitosis in the endometrial stroma during decidualization in the pseudopregnant rat. Biol Reprod 1983, 28:691-702.

37. Vogel KG, Trotter JA: The effect of proteoglycan on the morphology of collagen fibrils formed in vitro. Coll Relat Res 1987, 7:105-114.

38. Ameye L, Aria D, Jepsen K, Oldberg A, Xu T, Young MF: Abnormal collagen fibrils in tendons of biglycan/fibromodulin-deficient mice lead to gait impairment, ectopic ossification, and osteoarthritis. FASEB J 2002, 16:673-680.

39. Sanches JCT, Jones CJP, Aplin JD, lozzo RV, Zorn TMT, Oliveira SFO: Collagen fibril organization in the pregnant endometrium of decorindeficient mice. J Anat 2010, 216:144-155.

40. Chakravarti S: Functions of lumican and fibromodulin: lessons from knockout mice. Glycoconj J 2003, 19(4-5):287-293.

41. Markiewicz M, Asano Y, Znoyko S, Gong Y, Watson DK, Trojanowska M: Distinct effects of gonadectomy in male and female mice on collagen fibrillogenesis in the skin. J Dermatol Sci 2007, 47:217-226.

42. Hong SH, Nah HY, Lee JY, Gye MC, Kim CH, Kim MK: Analysis of estrogenregulated genes in mouse uterus using CDNA microarray and laser capture microdissection. J Endocrinol 2004, 181:157-167.

43. Tasheva ES, Corpuz LM, Funderburgh JL, Conrad GW: Differential splicing and alternative polyadenylation generate multiple mimecan mRNA transcripts. J Biol Chem 1997, 272(51):32551-32556.

44. Levens E, Luo X, Ding L, Williams RS, Chegini N: Fibromodulin is expressed in leiomyoma and myometrium and regulated by gonadotropinreleasing hormone analogue therapy and TGF-beta through Smad and MAPK-mediated signalling. Mol Hum Reprod 2005, 11:489-494.

45. Schaefer L, Gröne HJ, Raslik I, Robenek K, Ugorcakova J, Budny S, Schaefer RM, Kresse HI: Small proteoglycans of normal adult human kidney: distinct expression patterns of decorin, biglycan, fibromodulin, and lumican. Kidney Int 2000, 58:1557-1568.

46. Qian H, Fan MW, Xiao Y, Bartold PM: Immunohistochemical localization and expression of fibromodulin in the periodontium. Zhonghua Yi Xue Za Zhi 2003, 83:1682-1685.

47. Kim MR, Park DW, Lee JH, Choi DS, Hwang KJ, Ryu HS, Min CK: Progesterone-dependent release of transforming growth factor-beta1 from epithelial cells enhances the endometrial decidualization by turning on the Smad signaling in stromal cells. Mol Hum Reprod 2005, 11:801-808.

48. Das SK, Flanders KC, Andrews GK, Dey SK: Expression of transforming growth factor- $\beta$ isoforms ( $\beta 2$ and $\beta 3$ ) in the mouse uterus: analysis of the periimplantation period and effects of ovarian steroids. Endocrinology 1992, 130(6):3459-3466.

49. De Luca A, Santra M, Baldi A, Giordano A, lozzo RV: Decorin-induced growth suppression is associated with up-regulation of p21, an inhibitor of cyclin-dependent kinases. J Biol Chem 1996, 271(31):18961-18965.
50. Monfort J, Tardif G, Reboul P, Mineau F, Roughley P, Pelletier JP, MartelPelletier J: Degradation of small leucine-rich repeat proteoglycans by matrix metalloprotease-13: identification of a new biglycan cleavage site. Arthritis Res Ther 2006, 8(1):R26.

51. Imai K, Hiramatsu A, Fukushima D, Pierschbacher MD, Okada Y: Degradation of decorin by matrix metalloproteinases: identification of the cleavage sites, kinetic analyses and transforming growth factorbeta1 release. Biochem J 1997, 322(Pt 3):809-814.

52. Russell DL, Doyle KMH, Ochsner SA, Sandy JD, Richards JS: Processing and localization of ADAMTS- 1 and proteolytic cleavage of versican during cumulus matrix expansion and ovulation. J Biol Chem 2003, 278:42330-42339.

53. Schauer RC: Effects of estradiol and progesterone on rat uterine ribonuclease inhibitor activity. Horm Metab Res 1991, 23:162-165.

54. Rao KS, Sirdeshmukh R, Gupta PD: Modulation of cytosolic RNase activity by endogenous RNase inhibitor in rat vaginal epithelial cell on estradiol administration. FEBS Lett 1994, 343:11-14.

55. Ing $\mathrm{NH}$ : Steroid hormones regulate gene expression posttranscriptionally by altering the stabilities of messenger RNAs. Biol Reprod 2005, 72:1290-1296.

56. Kim VN: Small RNAs: Classification, biogenesis, and function. Mol Cells 2005, 19(1):1-15

57. Delić D, Grosser C, Dkhil M, Al-Quraishy S, Wunderlich F: Testosteroneinduced upregulation of miRNAs in the female mouse liver. Steroids 2010, 75(12):998-1004.

58. Saceda M, Lindsey RK, Solomon H, Angeloni SV, Martin MB: Estradiol regulates estrogen receptor mRNA stability. J Steroid Biochem 1998, 66:113-120.

doi:10.1186/1477-7827-9-22

Cite this article as: Salgado et al:: Modulation of small leucine-rich proteoglycans (SLRPs) expression in the mouse uterus by estradiol and progesterone. Reproductive Biology and Endocrinology 2011 9:22.

\section{Submit your next manuscript to BioMed Central and take full advantage of:}

- Convenient online submission

- Thorough peer review

- No space constraints or color figure charges

- Immediate publication on acceptance

- Inclusion in PubMed, CAS, Scopus and Google Scholar

- Research which is freely available for redistribution

Submit your manuscript at www.biomedcentral.com/submit
C) Biomed Central 